\title{
Marital Satisfaction and Mental Health in Multiple Sclerosis Patients’ and Healthy Individuals’ Accordance to Sex
}

\author{
Bita Ajilchi ${ }^{1 *}$, Arezoo Shomali Oskoei ${ }^{2}$, Flor Rezaeai $\operatorname{Kargar}^{3}$ \\ ${ }^{1}$ Department of Psychology, Faculty of Human Science, \\ Science and Research Branch University, Islamic Azad University (IAU), Tehran, Iran \\ ${ }^{2}$ Department of Psychology, Faculty of Human Science, \\ Islamic Azad University of Rudehen (RIAU), Tehran, Iran \\ ${ }^{3}$ Department of Psychology and Social Science, Central Tehran Branch, \\ Islamic Azad University (IAU), Tehran, Iran \\ Email: *Ajilchi_b@yahoo.com
}

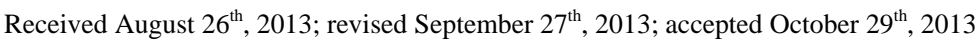

\begin{abstract}
Copyright ( $) 2013$ Bita Ajilchi et al. This is an open access article distributed under the Creative Commons Attribution License, which permits unrestricted use, distribution, and reproduction in any medium, provided the original work is properly cited.
\end{abstract}

\begin{abstract}
The aim of this study was to compare marital satisfaction and mental health in male and female multiple sclerosis patients with healthy males and females. In a correlation study, 59 MS patients in Tehran (31 female and 28 male, with a range of 25 to 55 years old) were selected by the random cluster sampling method and 59 healthy individuals were matched with them in sex and age. Then both groups filled in the marital satisfaction questionnaire of Enrich and GHQ. The test of multi-variance analysis showed that, regardless of the gender, for people with MS disease, the marital satisfaction and the whole of its subscales except the religion and the mental health and its all sub-scales, are established at a significantly low level. However, the comparison of these groups due to the gender showed that in the satisfaction elements and personality issues, the relationship between marital and leisure time of women patients is worse than men; however, healthy women scores in financial management are lower than healthy men. In addition, in the elements of mental health, women and men patients are similar to each other but healthy women have higher physical symptoms than healthy men $(P<.05)$. These results represent the necessity of applying approaches to increase the satisfaction of the marital and mental health of patients and training the couples for cooperation and higher perception.
\end{abstract}

Keywords: Multiple Sclerosis; Marital Satisfaction; Mental Health

\section{Introduction}

The disease of Multiple Sclerosis (MS) is a chronic progressive and disabling disease of the central neural system that is seen frequently among young people. Symptoms commonly include sensory disorder, infirmity, spasm, vision disorder, and cognitive disorder, trembling of limbs, disorder in urination, sexual functional disorder, and amnesia, auditory failure, blurring of vision and squinting in patients (Delisa, 1998; Levis, 2000; Nortvedt et al., 2007; Smeltzer \& Bar, 2008). Observations show that this disease is two or three times more common in women than men; it does not have a definite treatment and the aim of the treatment is to prevent the progressive disability from the chronic attacks, relapses and recurrence of the disease and or chronic progression of the disease (Compston Lassman, Ebers et al., 1998; Brown, 2005; Harrison, 2008). The nature and intensity of the symptoms of this disease appear in different fields of cognition, sensory factors and movement of the limbs. It also has a profound impact on the social and mental cognitive functions in the related patient (McReynolds, Koch, \& Rumrill, 1999). About $30 \%$ of these patients require home support being provided by couples in this case. (Buchanan, Radin,

\footnotetext{
*Corresponding author.
}

Chakravorty, \& Tyry, 2009). The greatest potential impacts of this disease can be the adaptive challenges with this disorder, having problems with marital relations and sexual function and family separation (Glantz, Chamberiain, Liu et al., 2009; Dennison Moss-Morris \& Chalder, 2009), reduction of marital satisfaction, decrease of satisfaction in physical intimacy and the reduction of relational levels (Perrone, Gordon, \& Tschopp, 2006). Indeed, the disease of MS affects intimacy and sexual relations in various ways. These impacts can appear as the reduction or a tendency to reluctance towards the sexual relations or difficulty in having friendly relations with his or her partner. These impacts are also from the direct changes of the related disease and or due to the struggles against the disease as well as adaptation with these impacts on the patient's life (Fully \& Varner, 2011; cited in Caleb, 2011). This kind of pressure of keeping a partner with chronic disease not only reduces the quality of marital relations but also damages any sexual relations between couples as well (O’Conner, McCabe, \& Firth, 2008). Along with this, Woollett and Edelmann (1988), in their research found that the marital satisfaction among couples with MS is lower than the same people without this disease. Also, McPheters and Sandberg (2010) in their studies found that the quality of couple relations has a positive relationship with physical functions of 
people with MS and that depression with physical function has a negative relationship with these patients. The quality of marital relations with a partner's depression has a negative relationship in both patients and couples. They concluded that couples with a high quality of marital relations can present with this disease as well. McCabe (2002) concluded that men with MS have higher sexual dysfunction than healthy men. Also, coping and level of cognitive function can be considered as the crucial predictors for the sexual satisfaction, sexual dysfunction and satisfaction of relations with couples in women with MS. People with MS face hard treatment, side effects, medication and physical disabilities along with psychological consequences are due to the unpredictable symptoms of the disease; this can also produce harmful factors such as being precluded from life targets, unemployment, disorder of income, frustrations with relationships, leisure time activities, the chores of daily life and the reduction of life quality and marital satisfaction (Jansen, 2003; Hakimo, 2000; cited in Dennison et al., 2009; Nort Wodet et al., 2007). In fact, along with these physical changes brought about by the disease, the psyche of these people is being affected by the related problems and physical limitations potentially annoying them. (Rugliatti, 2006; Janardan, 2002). In addition to this, the nature of this disease affects the sub-cortical and central neural areas of these patients and impacts on their mental health. (Jannati \& Azimi, 2002). Along with this, Mahmoodi, Nasiri and Niaz Azari (2008) found that there is a dysfunction of the mental health of people with MS so that they not only have intensely harsh physical problems, but also they suffer from social problems, anxiety and depression. Jahanbakhshian and Zandipour (2011) also found a significant difference between the mental health of people with MS and healthy ones. However, some researchers such as Malachy et al. (2007) in their studies concluded that many patients with MS report high levels of recovery or quality of personal life and social-psychological adjustment despite the main problems of physical health and considerable limitations of their social and interpersonal relations. These controversial issues in the results represent the lack of disease symptoms and healthy status in predicting the life quality, adaptation of the relations and mental health of these people. They show that there are other factors, of course. Johnson et al. (2004 cited in Malachy, 2007) consider this situation originated from the complex relationships between variables and different adaptive processes. McCabe (2002) has considered the cognitive levels and application of copings most useful in this case. It seems that another factor is most effective in these results but not observed in the background of this research; it is the gender that has been tested in the research that should be reviewed in this regard. One of the studies carried out on the women with MS has shown that the study of educational issues and speaking to an expert nurse of the MS disease reduces the problems related to the sexual relations among these people significantly. (Christopherson, 2006, cited in Kalb, 2011). Tompkins, Roeder, Thomas, Kimberly and Koch (2013) also found that the presentation of an enriched program to people with MS can recover their marital functions and psychological health in this regard. Researches carried out are as follows in this area: Fully et al. (2001); Gholikhani (2006); Saheb al Zamani and Rashvand (2007); Payamani et al. (2011); Shoaa Kazemi (2009). They also showed that the presentation of an optimized consulting program, supportive mental therapeutically, necessary training in relation to the disease, changing life styles, enhancing the religious element of coping, problem-solving, emotional rela- tions, marital satisfaction and satisfaction of sexual relations, can improve the mental health and life quality of these patients. According to what was stated before, in most research on people with MS, any differences were not observed in terms of the gender and, also, no other comparisons were found in this case. Hence, the present study has been fulfilled in relation to the mental health and marital satisfaction of people with MS in comparison to healthy people while considering the role of gender. Alongside this, the present study tries to respond to the question, what is the difference between healthy people and people with MS in terms of marital satisfaction and mental health according to gender. The hypotheses of study are:

1) There are difference between marital satisfaction of male and female with MS and healthy men and women.

2) There are difference between mental health of male and female with MS and healthy men and women.

\section{Method}

\section{Procedure}

The statistical community of the women and men with MS referred to MS clinics of the Tehran cosmopolitan research plan is of the correlation type. Among these clinics in Tehran, three clinics were selected by the random clustering method and all of the married people referred to these clinics including 59, (31 female and 28 male) ranging from 25 - 55 years old, were taken up for participation in this research and 59 healthy ones were assimilated in terms of age and gender. Then, both groups responded to the Enrich Satisfaction Questionnaire (1989) and Goldenberg Mental Health Questionnaire (GHQ; Goldenberg \& Hillier, 1972).

\section{Instrument}

\section{Enrich Marital Satisfaction Questionnaire}

This questionnaire is a 115 question tool applied for measureing the satisfaction level in marital relations and is composed of 14 sub-scales. The process of scoring is as $0,1,2,3,4$ of Likert type and the higher score shows the higher satisfaction. Olson et al. (1989) measured alpha coefficients for the marital satisfaction, personality issues, verbal relation, conflict resolution, financial management, leisure time, sexual relation, children and parenting, relatives and friends and the equal roles of men and women and they are as follows: .81, .73, .68, .75, .74 $.76, .48, .77, .72$, and .71. Soleimanian (1994) obtained the reliability of the questionnaire as .93 alpha coefficients. The correlation coefficient of this questionnaire was obtained with the scales of family satisfaction from .41 to .60 and with life satisfaction this was governed from .33 to .41 representing the signs of construct validity of the questionnaire (cited in Mohammadizadeh Ebrahimi, 2008). In the present study, Cronbach alpha obtained was .63.

\section{Mental Health Questionnaire (GHQ)}

This questionnaire was designed by Goldberg for the whole social community in 1972 including 28 questions measuring the mental status of people during one month; its minor scales are subjected to psychosomatic symptoms, anxiety and insomnia, social dysfunction and severe depression and it of course is a complete score. The most suitable scoring method is the use of the Likert simple pattern with scores of $0,1,2$, and 3 . The score 23 and higher represents the lack of mental health. The reliabil- 
ity using the correlation coefficient measurement has been reported as .87 with SCL90 (Babyvardi, 1997). Also, the correlation coefficient between four scales of the questionnaire is .33 to .61 (Jaafarnezhad, 2003). The reliability of this test has been measured in two different studies using Cronbach alpha coefficient .87 (Chan \& Chan, 1983) and .92. (Yazdanpanah, 2005, cited in Mohammadi, 2007). Cronbach alpha obtained is .83 in this research.

\section{Results}

According to Table 1, we found that both groups of patients and healthy people are assimilated together in variables of age and gender.

According to Table 2, there are differences between means of two groups. To assess significance of these differences ANOVA were used.

Table 3 shows that there is a significant difference between people with MS and healthy people in the variable of marital satisfaction and the whole of its sub-scales except the religious orientation. Also, in the comparison of the genders, there is a significant difference between the personality issues, children and parenting, relatives and friends and religious orientation. In addition to this, there is observed a significant difference between the interaction of the disease with gender of women with MS with men with this disease in comparison with healthy men and women in the personality issues, marital relations, financial management and leisure time activities $(p<.05)$.

As it shown in Table 4, it is observed that there is a significant difference between people with MS and healthy people in terms of mental health and the whole sub-scales related to this process. Also, in the process of interaction of the disease to the gender, there is found a significant difference between the psychosomatic symptoms elements $(p<.05)$.

\section{Discussion}

In the present study, according to Table $\mathbf{3}$, it is specified that regardless of the gender, people with MS have obtained lower grades than healthy ones in relation to the marital satisfaction and its whole sub-scales except the religious orientation. This result is coincident with the researches of Volvet and Edelman (1988), McCabe (2002), Prone et al. (2006), O’Conner et al. (2009), McPeters and Sandberg (2010). The lack of differences between people with MS and healthy people in the religious orientation represents the depth of religious beliefs in the Iranian population. Because, when they are faced with this kind of gigantic problem, the religious orientation cannot be changed in these people and their beliefs reduced in this regard. Meanwhile, belief in God and other religious resources can be established as a great supportive factor assisting them in the recovery of the disease. According to Shoaa Kazemi (2009), if these people have much religious belief when facing the disease, they will be more hopeful of overcoming their illness and having much better general health in this regard. Also Table 3 shows that without considering the related disease, women have got lower scores and grades than men in terms of personality issues, children and parenting, relatives and friends as well as religious orientation; but, in interaction of the disease to the gender, women have got lower grades than men in the personality issues, marital relations and leisure time activities in comparison to healthy people. In the element of financial management, it is
Table 1.

Demographical features and match evaluation of both groups.

\begin{tabular}{ccccccc}
\hline \multirow{2}{*}{ Variable } & \multicolumn{2}{c}{ MS group } & \multicolumn{5}{c}{ Healthy group } \\
\cline { 2 - 7 } & $\mathrm{M}^{\mathrm{a}}$ & $\mathrm{Sd}^{\mathrm{b}}$ & $\mathrm{M}$ & $\mathrm{Sd}$ & $\mathrm{t}$ & Sig level \\
\hline Gender & 1.48 & .50 & 1.15 & .50 & .000 & 1.000 \\
Age & 2.70 & 1.16 & 2.75 & 1.30 & .224 & .823 \\
\hline
\end{tabular}

Note: ${ }^{\mathrm{a}} \mathrm{M}=$ Mean, ${ }^{\mathrm{b}} \mathrm{Sd}=$ Standard deviation.

Table 2.

Descriptive values of marital satisfaction and mental health of people with MS and healthy people accordance to gender.

\begin{tabular}{|c|c|c|c|c|c|}
\hline \multirow{2}{*}{ Variable } & \multirow{2}{*}{ Gender } & \multicolumn{2}{|c|}{ MS group } & \multicolumn{2}{|c|}{ Healthy group } \\
\hline & & M & Sd & M & Sd \\
\hline \multirow{2}{*}{$\begin{array}{c}\text { Marital } \\
\text { satisfaction }\end{array}$} & Male & 171.64 & 28.48 & 238.57 & 37.75 \\
\hline & Female & 149.42 & 39.40 & 240.10 & 37.29 \\
\hline \multirow{2}{*}{ Personality issues } & Male & 18.64 & 4.07 & 20.36 & 4.83 \\
\hline & Female & 13.97 & 6.22 & 19.20 & 4.47 \\
\hline \multirow{2}{*}{ Marital relations } & Male & 18.43 & 4.26 & 22.57 & 4.16 \\
\hline & Female & 15.00 & 5.25 & 22.87 & 4.91 \\
\hline \multirow{2}{*}{$\begin{array}{l}\text { Conflict } \\
\text { resolution }\end{array}$} & Male & 18.64 & 3.93 & 23.21 & 5.49 \\
\hline & Female & 15.39 & 5.91 & 23.42 & 5.92 \\
\hline \multirow{2}{*}{$\begin{array}{c}\text { Financial } \\
\text { management }\end{array}$} & Male & 17.14 & 4.38 & 27.00 & 5.90 \\
\hline & Female & 17.35 & 4.71 & 22.90 & 7.54 \\
\hline \multirow{2}{*}{$\begin{array}{l}\text { Leisure times } \\
\text { activities }\end{array}$} & Male & 18.64 & 4.05 & 21.07 & 5.34 \\
\hline & Female & 15.10 & 5.29 & 22.32 & 4.24 \\
\hline \multirow{2}{*}{$\begin{array}{c}\text { Sexual } \\
\text { Relations }\end{array}$} & Male & 17.14 & 5.40 & 23.00 & 6.34 \\
\hline & Female & 16.26 & 4.41 & 22.90 & 5.99 \\
\hline \multirow{2}{*}{$\begin{array}{l}\text { Children and } \\
\text { parenting }\end{array}$} & Male & 18.36 & 3.91 & 25.71 & 8.52 \\
\hline & Female & 16.74 & 4.86 & 21.26 & 11.12 \\
\hline \multirow{2}{*}{$\begin{array}{l}\text { Relatives and } \\
\text { friends }\end{array}$} & Male & 17.50 & 3.50 & 23.14 & 5.04 \\
\hline & Female & 16.13 & 3.55 & 21.19 & 4.55 \\
\hline \multirow{2}{*}{$\begin{array}{l}\text { Religious } \\
\text { orientation }\end{array}$} & Male & 19.00 & 4.13 & 19.36 & 8.85 \\
\hline & Female & 17.42 & 5.39 & 16.16 & 6.75 \\
\hline \multirow{2}{*}{ Mental health } & Male & 55.79 & 13.47 & 28.21 & 9.68 \\
\hline & Female & 53.19 & 11.18 & 31.71 & 9.17 \\
\hline \multirow{2}{*}{$\begin{array}{l}\text { Psychosomatic } \\
\text { symptoms }\end{array}$} & Male & 14.71 & 3.79 & 8.29 & 4.32 \\
\hline & Female & 13.97 & 3.80 & 10.84 & 4.30 \\
\hline \multirow{2}{*}{$\begin{array}{c}\text { Anxiety and } \\
\text { insomnia }\end{array}$} & Male & 15.00 & 4.24 & 7.00 & 3.09 \\
\hline & Female & 14.26 & 4.77 & 8.45 & 2.67 \\
\hline \multirow{2}{*}{$\begin{array}{c}\text { Social } \\
\text { dysfunction }\end{array}$} & Male & 14.64 & 3.50 & 8.57 & 1.79 \\
\hline & Female & 14.00 & 3.77 & 8.03 & 2.47 \\
\hline \multirow{2}{*}{$\begin{array}{c}\text { Severe } \\
\text { depression }\end{array}$} & Male & 11.43 & 4.16 & 4.36 & 3.56 \\
\hline & Female & 10.97 & 2.17 & 4.39 & 3.55 \\
\hline
\end{tabular}


Table 3.

Group difference for the marital satisfaction of people with MS and healthy people accordance to the gender.

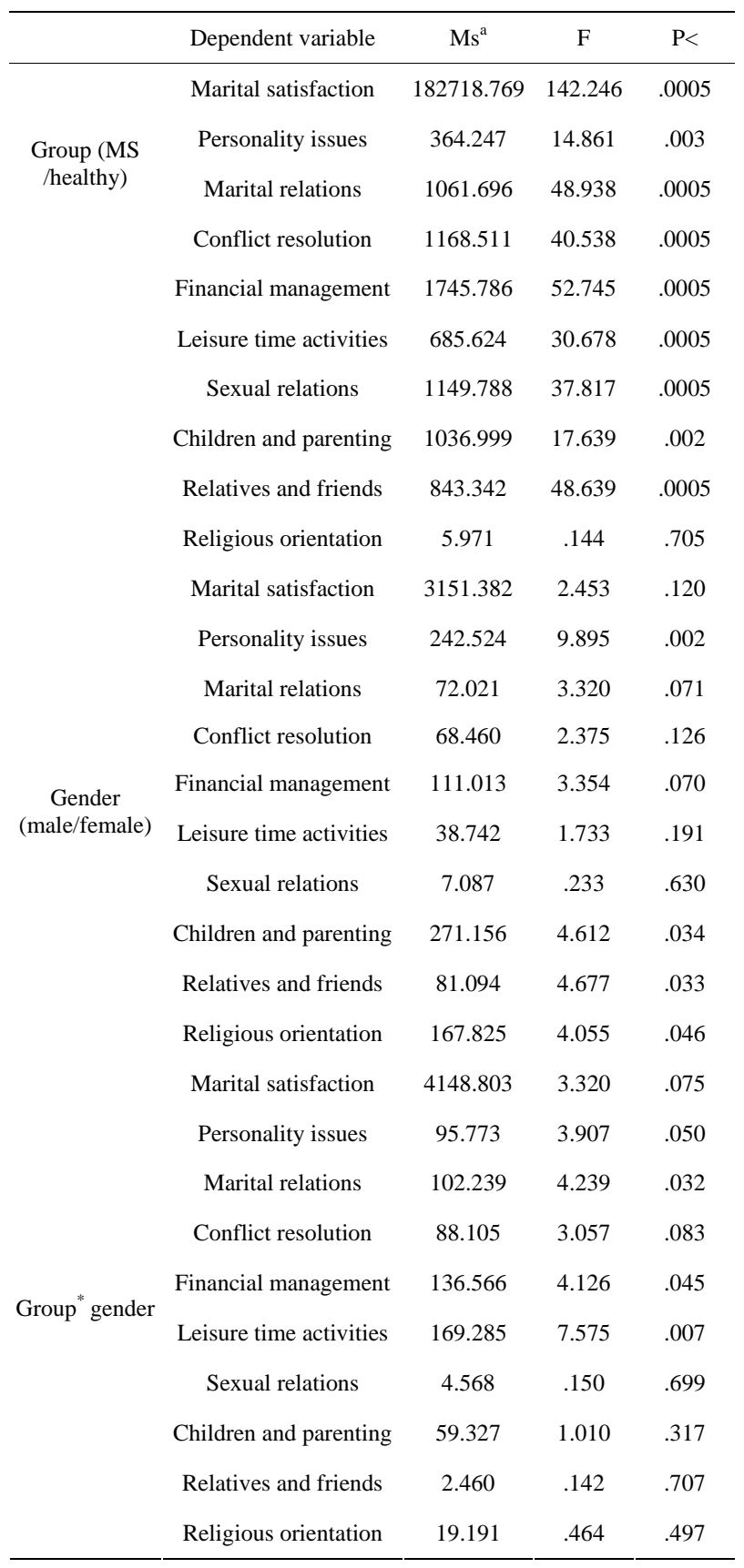

Note: ${ }^{a}$ Mean squares, $\mathrm{Df}=1$.

observed that healthy women are significantly lower than healthy men in comparison to the patients. In this relationship, it can be stated that excitement impairments happen in response to the beginning of the disability from the disease; this can affect the couples making their independence and intimacy change completely. The change of role in this relationship, from a partner to a supporter, changes basically the dynamic of the relationship. Moreover, the impacts of the cognitive changes on this relationship should be considered. The existence of the disease's progressive conditions, the disease existence before be-
Table 4.

Group differences for the mental health of people with MS and healthy people accordance to the gender.

\begin{tabular}{|c|c|c|c|c|}
\hline & Dependent variable & Ms & $\mathrm{F}$ & $P<$ \\
\hline \multirow{5}{*}{$\begin{array}{l}\text { Group } \\
\text { MS/healthy }\end{array}$} & Mental health & 17701.48 & 150.27 & .0005 \\
\hline & $\begin{array}{l}\text { Psychosomatic } \\
\text { symptoms }\end{array}$ & 671.95 & 41.48 & .0005 \\
\hline & Anxiety & 1402.17 & 99.06 & .0005 \\
\hline & Social dysfunction & 1066.18 & 120.31 & .0005 \\
\hline & Severe depression & 1370.99 & 120.26 & .0005 \\
\hline \multirow{5}{*}{$\begin{array}{c}\text { Gender } \\
\text { male/female }\end{array}$} & Mental health & 6.00 & .05 & .822 \\
\hline & $\begin{array}{l}\text { Psychosomatic } \\
\text { symptoms }\end{array}$ & 24.00 & 1.48 & .23 \\
\hline & Anxiety & 3.71 & .26 & .61 \\
\hline & Social dysfunction & 10.28 & 2.16 & 28 \\
\hline & Severe depression & 1.37 & .12 & .73 \\
\hline \multirow{5}{*}{ Group* gender } & Mental health & 272.60 & 2.31 & .13 \\
\hline & $\begin{array}{l}\text { Psychosomatic } \\
\text { symptoms }\end{array}$ & 80.08 & 4.94 & .03 \\
\hline & Anxiety & 35.394 & 2.501 & .117 \\
\hline & Social dysfunction & .079 & .009 & .925 \\
\hline & Severe depression & 1.772 & .155 & .694 \\
\hline
\end{tabular}

Note: ${ }^{*}$ means interaction between group and gender.

ginning relationship or marriage, and sexual dysfunction are the most essential factors making the related process dangerous in this regard (Chandler \& Brown, 1998; Halvorsen \& Metz, 1992; Volvet \& Edelman, 1988). The above mentioned factors can destroy and devastate these people's personality through reducing the stability of excitement, unsuitable copings and adaptations, and unawareness of accurate information in this relationship and the feeling of hopelessness. Since people have difficulties solving their problems together, the process of intimacy and quality of relations between them play a key role in this case. The reduction and change of leisure time activities can also result from these people's economical, cultural, mental and social issues. Based on the findings of the present study, the above-mentioned subjects are more accurate with women representing that women are more susceptible to this disease than men, significantly in terms of cognition and excitement. In other words, the physical, social, supportive and cognitive limitations of the disease can influence the personality issues, marital relations and leisure time of women significantly. Men with MS also have these problems due to the same mentioned limitations as women. Indeed, due to the loss of occupational situations, wrecked functioning and problems regarding the progression of the disease take these people's financial functioning out of their control; however, healthy men have better functioning in financial issues. Also, according to Table 4, we found that, regardless of the gender, people with MS have lower mental health than healthy ones significantly. The results of the above mentioned research are coincident with researches of Rogliati (2006), Janardan (2002), McPeters and Sandberg (2010), Mahmoodi et al. (2008), Jahanbakhshian and Zandi (2011). 
Also, regardless of the disease, no greater significant variables in women than men were observed. But in interactions of the disease with the gender, both men and women with this disease are not different in terms of mental health but healthy women have higher psychosomatic symptoms than healthy men in comparison to men and women with MS. It should be mentioned that it is apparent that these patients show greater symptoms due to the nature of the disease than healthy people. However, males and females with this disease have similar symptoms of the disease while in healthy people physical signs have been shown in women more than men. The results of the present study indicate that, in addition to the given approaches and necessary training in the field of enriching the marital relations and upgrading the quality of the mental health of these patients and their spouses, presentation of cognitive education and more support to recover the status of the personality issues and marital relations of women with this disease and preparation of suitable activities for their leisure time can be a great approach and may be a vital way to reduce the symptoms of this disease as well. The population of people with MS is limited to Tehran city, small sample size and inconsideration of illness sever levels are limitations of this study. According to this, wider research society, bigger sample size and categorizing the sample based on levels of illness are suggested for future studies.

\section{REFERENCES}

Buchanan, R. J., Radin, D., Chakravorty, B., \& Tyry, T. (2009). Informal care giving to more disabled people with multiple sclerosis. Disability Rehabilitant, 31, 1244-1256. http://dx.doi.org/10.1080/09638280802532779

Chandler, B. J., \& Brown, S. (1998). Sex and relationship dysfunction in neurological disability. Journal of Neurology, Neurosurgery and Psychiatry, 65, 877-880. http://dx.doi.org/10.1136/jnnp.65.6.877

Compston, A., Ebers, G. E., Lassmann, H., Mcdonald, I., Mathews, B., \& Wekerle, H. (1998). McAlpine's multiple sclerosis. London: Churchill Livingston.

Delisa, J. A. (1998). Rehabilitation medicine: Principles and practice (3rd ed.). Philadelphia: Lippincott Ranen Publisher.

Dennison, L., Moss-Morris, R., \& Chalder, T. (2009). A review of psychological correlates of adjustment in patients with multiple sclerosis. Clinical Psychology Review, 29, 141-153. http://dx.doi.org/10.1016/j.cpr.2008.12.001

Foley, F. W., \& Werner, M. A. (2012). How MS affects sexuality and intimacy. In Rosalind Kalb (Ed.), Multiple sclerosis, (5th ed.). New York: Demos Medical Publishing, 147-180.

Foley, F. W., LaRocca, N. G., Sanders, A. S., \& Zemon, V. (2001). Rehabilitation of intimacy and sexual dysfunction in couples with multiple sclerosis. Multiple Sclerosis, 7, 417-421.

Gholikhani, Z. (2006). The effect of grouping supportive psychotherapy on decrease depression and increase marital adjustment in female M.S. patients. Master's Dissertation, Persian: Shahid Beheshti University.

Glantz, M. J., Chamberlain, M. C., Liu, Q. et al. (2009). Gender disparity in the rate of partner abandonment in patients with serious medical illness. Cancer, 115, 5237-5242. http://dx.doi.org/10.1002/cncr.24577

Halvorsen, J. G., \& Metz, M. E. (1992). Sexual dysfunction, part 1: Classification, etiology and pathogenesis. Journal of American Board and Family Practice, 5, 51-61.

Harrison, M. O. (2008). International review of psychiatry. Psychiatric Services, 1, 1-7.

Jahanbakhshian, N., \& Zandipour, T. (2011). A study on the effectiveness of group counseling based on Lazarus multimodal approach with relapsing/remitting MS patients on the improvement of mental health \& social support of patients. Journal of Psychological Studies,
7, 65-74.

Janardhan, V., \& Backsi, R. (2002). Quality of life in patients with multiple sclerosis: The impact of fatigue and depression. Journal of Neurology Science, 205, 51-58. http://dx.doi.org/10.1016/S0022-510X(02)00312-X

Janatti, I., Azimi, H., \& Mahmmodi, Gh. (2002). Psychiatric nursing. Tehran: Salemi.

Levis, R. (2000). Merritt's neurology (10th ed.). Philadelphia: Lippincott Williams \& Wilkins.

Mahmoodi, Gh., Nassiri, A., \& Niazazari, K. (2008). Mental health in M.S. patients in Mazandaran province in 2007. Journal of Mazandaran Medical University, 18, 70-73.

Malachy, B., Donald, M. S., \& Lindsey, S. (2007). Psychological adaptation and quality of life in multiple sclerosis: Assessment of the disability centrality model. Journal of Rehabilitation, 1, 245-251.

Marvin, D. W. (2000). Multiple sclerosis: Continuing mysteries and current management. Drug Top, 144, 93-102.

McCabe, M. P. (2002). Relationship functioning and sexuality among people with multiple sclerosis. Journal of Sex Research, 39, 302-309. http://dx.doi.org/10.1080/00224490209552154

McPheters, J. K., \& Sandberg, J. G. (2010). The relationship among couple relationship quality, physical functioning, and depression in multiple sclerosis patients and partners. Families, Systems, \& Health, 28, 48-68. http://dx.doi.org/10.1037/a0018818

McReynolds, C. J., Koch, L. C., \& Rumrill, P. D. (1999). Psychosocial adjustment to multiple sclerosis: Implication for rehabilitation professionals. Journal of Vocational Rehabilitation, 12, 83-91.

Mohammadi, Sh. (2007). The relationship between personality traits and general health in male and female teachers of Tehran. Journal of Applied Psychology, 1, 269-284.

Morgante L. (2000). Hope in multiple sclerosis, a nursing perspective. International Journal of MS Care, 2, 3. http://dx.doi.org/10.7224/1537-2073-2.2.9

Nortvedt, M. W., Rise, T., Frugaard, J., Mohn, J., Bakke, A., Skar, A. B., Nyland, H., Glad, S. B., \& Myhr, K.-M. (2007). Prevalence of bladder, bowel and sexual problems among multiple sclerosis patients two to five years after diagnosis. Multiple Sclerosis Journal, 13, 106-112. http://dx.doi.org/10.1177/1352458506071210

O'Connor, E. J., McCabe, M., \& Firth, L. (2008). The impact of neurological illness on marital relationships. Journal of Sex Marital Therapy, 34, 115-132. http://dx.doi.org/10.1080/00926230701636189

Payamani, F., Nazari, A. A., Noktehdan, H., Mehran, A., \& Sahraian, M. A. (2011). The study of M.S patient's life style referred to MS association in Tehran city in 2008. Yafteh, 48, 31-38.

Perrone, K., Gordon, P. A., \& Tschopp, M. K. (2006). Caregiver marital satisfaction when a spouse has multiple sclerosis. Journal of Applied Rehabilitant Counseling, 37, 26-32.

Rugliatti, M., Rosati, G., Carton, H., Riise, T., Drulovic, J., Vecsei, L., \& Milanov, I. (2006). The epidemiology of multiple sclerosis in Europe. European Journal of Neurology, 13, 700-702. http://dx.doi.org/10.1111/j.1468-1331.2006.01342.x

Sahebozzamani, M., \& Rashvand, F. (2008). The study of training demands of MS patients, members of Iran's MS Society in 2007. Medical Science Journal of Islamic Azad University Tehran Medical Branch, 53, 195-199.

Shoaa Kazemi, M. (2009). The relationship between religious coping strategies and mental health in Multiple Sclerosis patient (MS). Journal of Applied Psychology, 3, 57-66.

Smeltzer, S., \& Bar, B. (2008). Text book of medical-surgical nursing. Philadelphia: W.B. Saunders Co.

Tompkins, S. A., Roeder, J. A., Thomas, J. J., \& Koch, K. K. (2013). Effectiveness of a relationship enrichment program for couples living with multiple sclerosis. International Journal of MS Care, 15, 27-34. http://dx.doi.org/10.7224/1537-2073.2012-002

Woollett, S. L., \& Edelmann, R. J. (1988). Marital satisfaction in individuals with multiple sclerosis and their partners; its interactive effect with life satisfaction, social networks and disability. Sexual and Marital Therapy, 3, 191-196. 